\title{
Epidemiological analysis of 9,779 burn patients in China: An eight-year retrospective study at a major burn center in southwest China
}

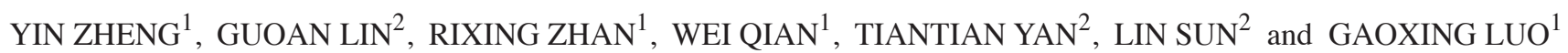 \\ ${ }^{1}$ Institute of Burn Research, State Key Laboratory of Trauma, Burn and Combined Injury, Key Laboratory of \\ Disease Proteomics of Chongqing, Southwest Hospital, Army Medical University, Chongqing 400038; ${ }^{2}$ Military Burn Center, \\ The 990th (159th) Hospital of The People's Liberation Army, Zhumadian, Henan 463000, P.R. China
}

Received June 27, 2018; Accepted November 30, 2018

DOI: $10.3892 /$ etm.2019.7240

\begin{abstract}
Burns are tissue injuries caused by high temperature, chemicals or electricity. Severe burns may involve all of the organs and tissues of the human body, leading to a series of pathophysiological processes and even death. The present study reviewed the clinical data of burn patients, including cases of burn-associated death, to provide evidence for the strategy of burn prevention. Basic information from 13,205 inpatients treated between January 1, 2009 and December 31, 2016 was extracted from the database of the Institute of Burn Research at Southwest Hospital (Chongqing, China). After excluding 3,426 inpatients who were not primarily treated for burns, 9,779 patients remained; among them, 68 cases $(0.7 \%)$ had died as a direct consequence of the burns. Based on baseline data, the mortality rate, total body surface area of the burn (TBSA), age, sex, cause of injury and complications were analysed. In general, males accounted for a higher percentage than female burn patients. Of the patients, $95.54 \%$ had a TBSA of $<50 \%$, and the rate of mortality of the patients was increased when the TBSA was $\geq 50 \%$. The major causes of injury were scalds (41.60\%), fire (26.92\%) and electricity (15.29\%), and the majority of victims were 14 years or younger. With improvements in burn treatment technology in recent years, burn patient mortality was significantly reduced. Complications, including multiple organ failure and severe systemic infection, may reduce the survival rate of patients. The major risk factors for death included burns resulting from explosions, as well as shock, age (aged $0-1$ or $\geq 50$ years), greater TBSA and
\end{abstract}

Correspondence to: Dr Gaoxing Luo, Institute of Burn Research, State Key Laboratory of Trauma, Burn and Combined Injury, Key Laboratory of Disease Proteomics of Chongqing, Southwest Hospital, Army Medical University, 29 Gaotanyan Street, Chongqing 400038, P.R. China

E-mail: logxw@yahoo.com

Key words: retrospective study, burn, complication, length of stay, mortality full-thickness burn area. With increasing length of stay at the hospital, patient mortality decreased. The renewal of treatment concepts and refined patient management contributed to the shorter LOS and lower mortality in 2015 and 2016.

\section{Introduction}

Burns are a common type of injury that may cause different degrees of impairment of the body's function and appearance, thus affecting the quality of life and placing a burden on the affected patients and their family; depending on the extent and degree, they may even be life-threatening. With the substantial development of industry and transportation, the demand and use of energy, oil and coal are rising, which increases the incidence of burns. It is estimated that $>10,000,000$ individuals suffer from burns every year in China, and, compared with the general population, the incidence rate of burn injury is increased in the coal, petroleum, chemical and metallurgical industries (1). According to statistics, burns are the fourth most common type of injury in the world, ranking behind traffic accidents, falls and intentional injuries. It is estimated that 100 million people are burned every year in the world, with $>10$ million requiring hospitalization, and $>200,000$ succumbing to mortality (2).

The treatment of patients with a large total body surface area of the burn (TBSA) or a large full-thickness burn area is challenging. A burn is not only a type of local injury but also a complex systemic disease that is difficult to treat, and the associated mortality and disability rates are high. According to UK data, there are $\sim 13,000$ hospitalized burn casualties and 300 deaths annually in the UK, with a mortality rate of $2.31 \%$ (3). The occurrence of a burn brings great trauma to the patient, their family and society, and the burden is not only physical but also psychological and economic in nature. In the previous decades, the quality of burn treatments in China has markedly improved and the survival rate of burn patients has significantly increased. However, reducing the incidence of burns has also become a practical challenge (1).

Recently, numerous scholars have categorized burns according to patient age, including pediatric burns (4) and geriatric burns (5), the cause of injury, including electrical 
injury (6) and chemical burns (7), and the location of the burn, e.g., hand burns (8) and auricular burns (9); however, studies providing an overall analysis are rare, and epidemiological data for burn patients vary between locations due to regional, climatic and human factors.

In the present study, 9,779 burn patients hospitalized at Southwest Hospital between January 2009 and December 2016 were retrospectively analysed. Among them, 68 deaths occurred, resulting in a mortality rate of $0.7 \%$. After collecting relevant information, the general condition, cause of injury, burn area and complications of the burn patients were analyzed and conclusions were drawn from these analyses. An accurate determination of the degree of the burn may enable medical staff to make a more objective clinical diagnosis and effective treatment. Furthermore, a retrospective analysis of clinical cases may provide suggestions for implementing further burn prevention strategies in southwest China aimed at seasonal and regional characteristics.

\section{Materials and methods}

Clinical data. The data of burn patients $(\mathrm{n}=13,205)$ who were admitted to the Southwest Hospital of the Army Medical University (Chongqing, China) between January 1, 2009 and December 31, 2016 were retrieved from the hospital's Electronic Medical Record System. Patients without acute burn injuries (i.e., those with scarring, cosmetic problems or chronic wounds), were excluded $(n=3,426)$. The medical records of the hospitalized patients were reviewed, including demographic information, causes of and factors associated with the injury, pre-hospital and hospital treatment and demographic data (age, gender, residential area, admission date and discharge date), injury-associated data (condition of the burn, etiology of burn injuries, TBSA and degree of burn), major complications and the treatment outcomes (cure, improvement, abandon treatment or death).

Statistical analysis. After the data were collected and listed using Excel 2007 (Microsoft Corp., Redmond, WA, USA), the statistical software SPSS 20.0 (IBM Corp., Armonk, NY, USA) was used to perform analysis of variance, followed by Fisher's least significant difference post hoc test and the $\chi^{2}$ test between different groups. The mean \pm standard deviation or the median [interquartile range (IQR)] was used to describe the dispersion of variables among the statistical data. The Mann-Whitney U-test was performed to compare two or more medians of categorical variables (age, gender, type of burn, outcome). Multivariate logistic regression analysis was used to screen for risk factors for burn patients. The $\chi^{2}$ test was used for pairwise and multi-group comparisons. $\mathrm{P}<0.05$ was considered to indicate a statistically significant difference.

\section{Results}

General analysis. During the period from 2009 to 2016, 13,205 burn patients were admitted to the Burn Research Institute of Southwest Hospital of the Army Medical University (Chongqing, China). After excluding 3,426 inpatients who were not mainly treated for burns, 9,779 patients were retained. Among them, 6,560 (67.1\%) were male and
Table I. General data of the hospitalized patients $(n=9,779)$.

\begin{tabular}{|c|c|}
\hline Characteristics & Value \\
\hline \multicolumn{2}{|l|}{ Gender } \\
\hline Male & $6,560(67.1)$ \\
\hline Female & $3,219(32.9)$ \\
\hline \multicolumn{2}{|l|}{ Age (years) } \\
\hline $0-1$ & $1,807(18.5)$ \\
\hline $2-14$ & $2,027(20.7)$ \\
\hline $15-24$ & $806(8.2)$ \\
\hline $25-49$ & $3,535(36.1)$ \\
\hline$\geq 50$ & $1,604(16.4)$ \\
\hline \multicolumn{2}{|l|}{ Residence } \\
\hline Chongqing & $7,237(74.0)$ \\
\hline Sichuan & $1,628(16.6)$ \\
\hline Guizhou & $518(5.3)$ \\
\hline Others & $396(4.0)$ \\
\hline \multicolumn{2}{|l|}{ Season of burn } \\
\hline Spring & $2,520(25.8)$ \\
\hline Summer & $2,768(28.3)$ \\
\hline Autumn & $2,173(22.2)$ \\
\hline Winter & $2,318(23.7)$ \\
\hline \multicolumn{2}{|l|}{ Outcome } \\
\hline Death & $68(0.7)$ \\
\hline Cure & $9,629(98.5)$ \\
\hline Abandon treatment & $75(0.8)$ \\
\hline Improvement & $7(0.07)$ \\
\hline \multicolumn{2}{|l|}{ Shock } \\
\hline Yes & $230(2.4)$ \\
\hline No & $9,549(97.6)$ \\
\hline \multicolumn{2}{|l|}{ Inhalation injury } \\
\hline Yes & $412(4.2)$ \\
\hline No & $9,367(95.8)$ \\
\hline \multicolumn{2}{|l|}{ Complications } \\
\hline Yes & $141(1.4)$ \\
\hline No & $9,638(98.6)$ \\
\hline Total burn area (\%) & $8(4-15)$ \\
\hline Full-thickness burn area (\%) & $0(0-2)$ \\
\hline Length of hospital stay (days) & $17(9-33)$ \\
\hline
\end{tabular}

Values are expressed as $\mathrm{n}(\%)$ or as median (interquartile range).

3,219 (32.9\%) were female. The burn patients covered each age group, with those aged 25-49 years accounting for the largest proportion at $36.1 \%$. The patients were mainly from Chongqing, followed by Sichuan and Guizhou. The median and IQR of the length of stay was 17 (8-33) days. The group aged 0-1 years included almost the same number of patients as that of the group aged 2-14 years. According to a statistical analysis, the mortality rate was only $0.7 \%$. The medians and IQRs of the TBSA and full-thickness burn area for all patients are presented in Table I. When formulating a burn prevention strategy, it is required to consider not only the characteristics 


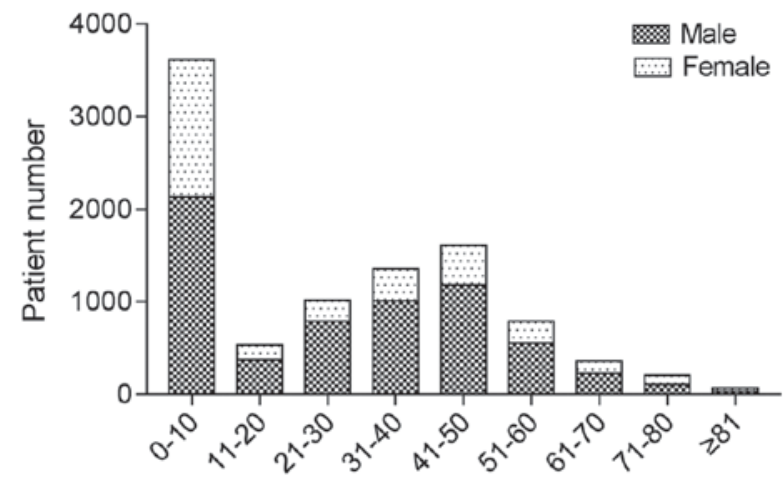

Figure 1. Distribution of burns by age group (years) and gender ratio.

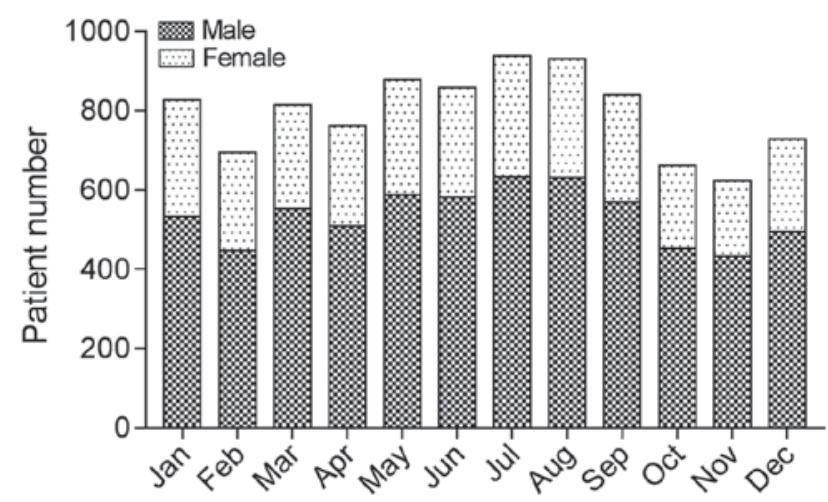

Figure 2. Distribution of burns by month.

of the burn itself but also the distribution, season, climate and human factors of the local population. Male inpatients were more common than female inpatients. The proportions of burn patients admitted in the Spring, Summer, Autumn and Winter were $25.8,28.3,22.2$ and $23.7 \%$, respectively, with the proportion being slightly higher in the Summer (Figs. 1-4).

Analysis of the burn patients regarding gender and age. The 0 -10-year-old group had the largest number of burns and included more males than females (Fig. 1). In the 0-1-year-old age group, no significant difference was observed among the patients in terms of gender and causes of injury. In the group of patients aged $\geq 2$ years, significant differences in the cause of the burn between different genders were identified (Table II). With the increase in age, the number of patients with burn injuries decreased. Of note, 2,637 male patients and 898 female patients were included in the 25-49-year-old group. As presented in Table II, the number of male burn patients was higher than that of females. After dividing the patients into 5 different age groups, a significant difference in the cause of injury by gender in the 0-1-year-old age group was identified, while significant differences were present in the other age groups $(\mathrm{P}<0.01$; Table II). Analysis of the TBSA by gender revealed no significant differences $(\mathrm{P}>0.05$; Table III).

Analysis of the TBSA. Among all of the hospitalized patients, the minimum TBSA was $0.1 \%$ and the maximum TBSA was $100 \%$. The groups with a TBSA of $0-5$ and $6-15 \%$ included more burn victims but fewer deaths compared with those

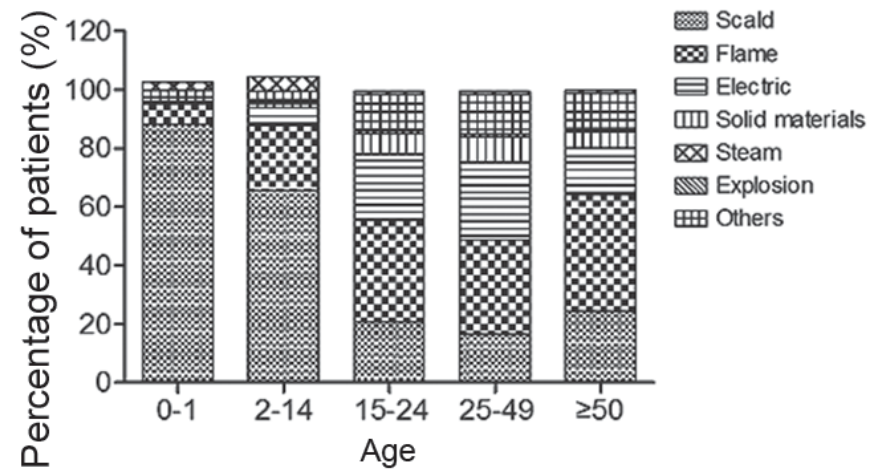

Figure 3. Distribution of etiology by age group (years).

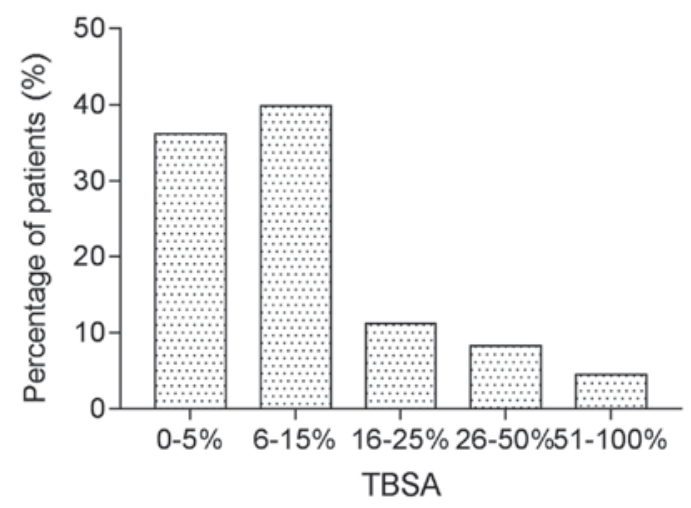

Figure 4. Distribution of \%TBSA for all patients. TBSA, total body surface area.

in the groups with a higher TBSA. With the increase in the TBSA, the number of deaths increases gradually (Table IV). The number of deaths increased significantly when the TBSA was $>50 \%$, although the number of cases in that group was lower than that in the groups with a lower TBSA.

Association of TBSA with the cause of burns and length of hospital stay (LOS). Scalding, flame and electricity were the major causes of burn injury, followed by solid materials and hot steam. A significant difference was identified in the TBSA between different burn types and in-hospital mortality (Table V). Other causes of burns mainly included infrared, ultraviolet and high-temperature dust (data not shown). Among all causes of burn injury, the death rate of patients with chemical burns was highest, as the burn degree was deeper and the complications were more serious (results not shown) (10). Recently, with the renewal of treatment concepts and the refinement of the management of burn patients, the importance of the LOS of burn patients has gradually been emphasized These new treatment concepts and patient management contribute to the shorter LOS and lower mortality in 2015 and 2016 (Fig. 5).

Analysis of the causes of death. Clinicians face numerous difficulties when treating burns. The factors that may affect the survival of burn patients include widespread complications, patient age, burn area and tolerance to injury. As determining the sole cause of death for a patient is difficult, the present study focused on the patients who succumbed to mortality 
Table II. Causes of burns by gender and age.

\begin{tabular}{|c|c|c|c|c|c|c|c|c|c|}
\hline $\begin{array}{c}\text { Age } \\
\text { (years)/gender }\end{array}$ & Scalds & Flame & Electric & $\begin{array}{c}\text { Solid } \\
\text { materials }\end{array}$ & Steam & Explosion & Others & $\chi^{2}$ & P-value \\
\hline \multicolumn{10}{|l|}{$0-1$} \\
\hline Male & $951(9.72)$ & $76(0.78)$ & $6(0.06)$ & $13(0.13)$ & $4(0.04)$ & $0(0.00)$ & $28(0.29)$ & \multirow[t]{2}{*}{0.544} & \multirow[t]{2}{*}{0.995} \\
\hline Female & $641(6.55)$ & $53(5.42)$ & $5(0.51)$ & $10(1.02)$ & $2(0.20)$ & $0(0.00)$ & $18(1.84)$ & & \\
\hline \multicolumn{10}{|l|}{$2-14$} \\
\hline Male & $734(7.51)$ & $298(3.05)$ & $87(0.89)$ & $15(0.15)$ & $7(0.07)$ & $12(0.12)$ & $46(0.47)$ & \multirow[t]{2}{*}{31.919} & \multirow[t]{2}{*}{$<0.001$} \\
\hline Female & $599(6.13)$ & $150(1.53)$ & $31(0.32)$ & $12(0.12)$ & $5(0.05)$ & $4(0.04)$ & $27(0.28)$ & & \\
\hline \multicolumn{10}{|l|}{$15-24$} \\
\hline Male & $95(0.97)$ & $199(2.03)$ & $179(1.83)$ & $41(0.42)$ & $8(0.08)$ & $5(0.05)$ & $71(0.73)$ & \multirow[t]{2}{*}{85.87} & \multirow[t]{2}{*}{$<0.001$} \\
\hline Female & $74(0.76)$ & $79(0.81)$ & $4(0.04)$ & $14(0.14)$ & $6(0.06)$ & $3(0.03)$ & $28(0.29)$ & & \\
\hline \multicolumn{10}{|l|}{$25-49$} \\
\hline Male & $266(2.72)$ & $808(8.26)$ & $890(9.10)$ & $277(2.83)$ & $33(0.34)$ & $30(0.31)$ & $333(3.41)$ & \multirow[t]{2}{*}{520.113} & \multirow[t]{2}{*}{$<0.001$} \\
\hline Female & $319(3.26)$ & $326(3.33)$ & $44(0.45)$ & $39(0.40)$ & $21(0.21)$ & $6(0.06)$ & $143(1.46)$ & & \\
\hline \multicolumn{10}{|l|}{$\geq 50$} \\
\hline Male & $169(1.73)$ & $417(4.26)$ & $228(2.33)$ & $72(0.74)$ & $15(0.15)$ & $12(0.12)$ & $135(1.38)$ & \multirow[t]{2}{*}{170.027} & \multirow[t]{2}{*}{$<0.001$} \\
\hline Female & $220(2.25)$ & $226(2.31)$ & $22(0.22)$ & $18(0.18)$ & $8(0.08)$ & $1(0.01)$ & $61(0.62)$ & & \\
\hline \multicolumn{10}{|l|}{ Total } \\
\hline Male & $2,215(22.65)$ & 1,798 (18.39) & $1,390(14.21)$ & $418(4.27)$ & $67(0.69)$ & $59(0.60)$ & $613(6.27)$ & \multirow[t]{2}{*}{807.114} & \multirow[t]{2}{*}{$<0.001$} \\
\hline Female & $1,853(18.95)$ & $834(8.53)$ & $106(1.08)$ & $93(0.95)$ & $42(0.43)$ & $14(0.14)$ & $277(2.83)$ & & \\
\hline
\end{tabular}

Values are expressed as $\mathrm{n}(\%)$. Statistical analysis among multiple groups was performed using the Chi-square test. $\mathrm{P} \leq 0.05$ was considered to indicate a statistically significant difference.

Table III. Burn TBSA by gender and age group.

\begin{tabular}{llcr}
\hline Parameters & TBSA & $\chi^{2}$ & P-value \\
\hline Gender & & & \\
Male & $8(4-15)$ & -0.440 & 0.660 \\
Female & $8(4-15)$ & & \\
Age (years) & & & $<0.001$ \\
$0-1$ & $8(5-13)$ & 57.309 & \\
$2-14$ & $8(5-15)$ & & \\
$15-24$ & $6(2-15)$ & & \\
$25-49$ & $8(3-17)$ & & \\
$\geq 50$ & $7(2-16)$ & & \\
\hline
\end{tabular}

Values are expressed as the median (IQR). Statistical analysis within the IQRs was performed using the Mann-Whitney U-test. $\mathrm{P} \leq 0.05$ was considered to indicate a statistically significant difference. IQR, interquartile range; TBSA, total body surface area.

and aimed to identify what factors might increase their risk of death.

Among all of the cases that resulted in death, sepsis and organ complications (internal organ failure and bleeding) were the most common and major causes, although in certain cases, death occurred due to mild inhalation injury and shock. Statistical analysis indicated that the patients with more complications also had higher mortality rates. For instance, $29.41 \%$ of the burn patients with two types of complication
Table IV. Outcome of burns by sex and total burn area.

\begin{tabular}{llccc}
\hline TBSA (\%) & Sex & $\begin{array}{c}\text { Discharged } \\
(\mathrm{n})\end{array}$ & $\begin{array}{c}\text { Death } \\
(\mathrm{n})\end{array}$ & $\begin{array}{c}\text { Percentage } \\
\text { death }\end{array}$ \\
\hline $0-5$ & Male & 2,464 & 0 & 0.00 \\
& Female & 1,187 & 2 & 0.17 \\
$6-15$ & Male & 2,510 & 1 & 0.04 \\
& Female & 1,307 & 1 & 0.08 \\
$16-25$ & Male & 702 & 1 & 0.14 \\
& Female & 374 & 0 & 0.00 \\
$26-50$ & Male & 541 & 8 & 1.48 \\
& Female & 243 & 2 & 0.82 \\
$51-60$ & Male & 92 & 2 & 2.17 \\
& Female & 43 & 0 & 0.00 \\
$61-70$ & Male & 63 & 3 & 4.76 \\
& Female & 19 & 1 & 5.26 \\
$\geq 71$ & Male & 132 & 41 & 31.06 \\
& Female & 34 & 6 & 17.65 \\
\hline
\end{tabular}

TBSA, total body surface area.

died, while the mortality rate was $60.29 \%$ for the burn patients with three types of complication (Fig. 6). However, with the improvement in medical treatment and the high quality of nursing technology, a decline in the number of deaths induced by sepsis and organ complications has been observed. 
Table V. Total burn area by burn type and in-hospital mortality.

\begin{tabular}{lrrr}
\hline Item & TBSA & $\chi^{2}$ & P-value \\
\hline Cause of burn & & & \\
Scalds & $8(5-15)$ & $1,016.876$ & $<0.001$ \\
Flame & $10(5-25)$ & & \\
Electric & $5(2-10)$ & & \\
Solid materials & $2(1-7)$ & & \\
Steam & $7(3-15)$ & & \\
Explosion & $10(5-56)$ & & \\
Others & $3(1-12)$ & & \\
Outcome & & & \\
Death & $85(61-94)$ & -2.690 & \\
Cure & $8(4-15)$ & & \\
Abandon treatment & $10(5-52)$ & & \\
Improvement & $35(10-83)$ & & \\
\hline
\end{tabular}

Values are expressed as the median (IQR). Statistical analysis within the IQR was performed using the Mann-Whitney U-test. P $\leq 0.05$ was considered to indicate a statistically significant difference. IQR, interquartile range.

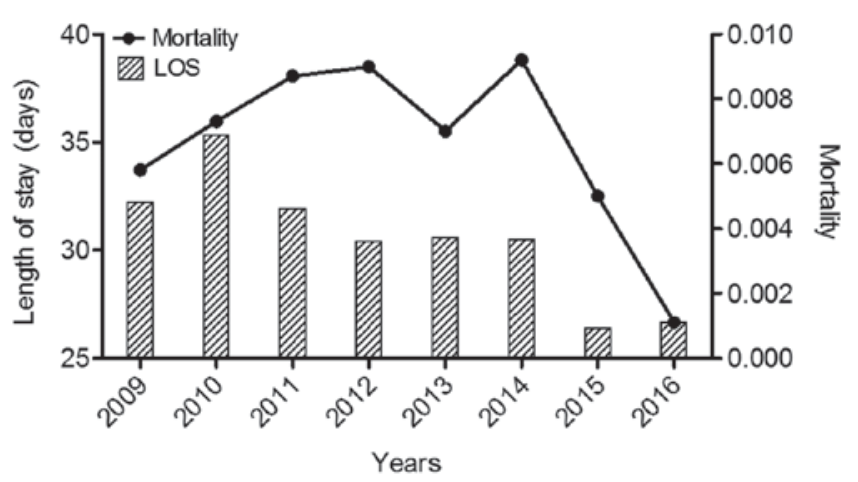

Figure 5. Distribution of LOS and \%TBSA for all patients. TBSA, total body surface area; LOS, length of hospital stay.

Risk factors for death of burn patients. The three major complications in burn patients are inhalation injury, shock and infection. In the present study, shock was selected as an index for multivariate analysis. Infection is mainly a matter that requires the attention of medical staff. In addition, certain studies have expressed doubt regarding inhalation injury as a prognostic factor in burn patients; prior to the popularization of the fibrotic bronchoscope at our institution, the diagnosis of inhalation injury mainly relied on the clinician's experience, this subjective assessment can sometimes be controversial (11). Therefore, inhalation injuries as an index affecting the risk of mortality of burn patients were not included.

First, single-factor analysis was used to screen and reassign multiple variables associated with death. Subsequently, the variables were subjected to analysis with multivariate logistic regression models. Next, the fitting method was used to screen six risk factors associated with burn-associated death. After sorting the factors according to their odds ratio, it was revealed that explosion, shock, age, TBSA and full-thickness burn area

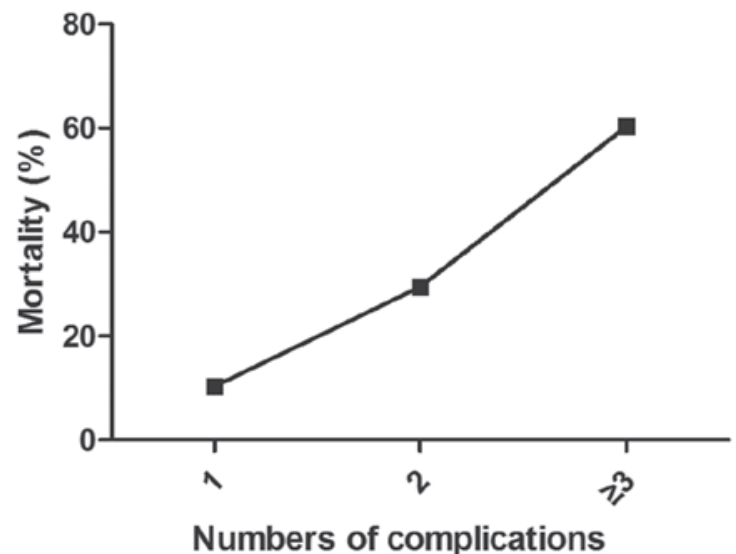

Figure 6 . The positive correlation between mortality and numbers of complications.

were risk factors for burn injury-associated death (Table VI). As presented in Table VII, patients injured by an explosion had the highest OR. Therefore, the mortality rate of these patients is higher (12-14); indeed, the mortality rate of burn patients injured by explosions was reported to be $38.46 \%$ (15). With the increased LOS, the patient mortality decreased (regression coefficient, $-0.020 ; \mathrm{P}<0.001)$.

\section{Discussion}

There are certain limitations of the present study. For example, the protocol did not assess the degree of the burns. Secondly the study only analyzed a single burn treatment center, thus the analysis results may only represent the situation of burns in a certain area. Whether the findings can be popularized and used nationwide remains to be discussed.

Retrospective analysis of patients' medical records from a hospital's database may not only provide summaries to improve the treatment technology, but also a reference for the formulation of burn prevention strategies in the future. Of note, the present study indicated that the number of male burn patients was higher than that of females, which may be due to differences between male and female occupations and activities. Therefore, when formulating burn prevention strategies, age factors should also be distinguished. After 2 years of age, children begin to attend early childhood classes and kindergartens, and teachers should perform burn prevention education as a strategy to reduce the number of burn injuries. Furthermore, the present study indicated that the proportion of burn patients in the 25-49 year-old group was higher than the other four groups, perhaps due to the greater exposure of these people to certain heat sources and the resulting increase in the probability of contracting burn injuries, whereas the number of children with scalds was much higher, and therefore, enforcement of post-school safety education is particularly important. In addition, a risk factor analysis may provide guidance for clinical treatment (16).

In the present study, statistical analysis of the clinical data suggested that the patients hospitalized at Southwest Hospital (Chongqing, China) mostly lived in Chongqing and Sichuan province of China. Chongqing is also known as the "mountain city'; the resident population is mainly composed of individuals 
Table VI. Univariate logistic regression analysis of factors associated with mortality.

\begin{tabular}{lccrcc}
\hline Variables & $\begin{array}{c}\text { Regression } \\
\text { coefficient }\end{array}$ & Standard error & Wald & P-value & OR (95\% CI) \\
\hline Age & 0.659 & 0.121 & 29.456 & $<0.001$ & $1.932(1.523-2.451)$ \\
Explosion & 4.988 & 0.510 & 95.519 & $<0.001$ & $146.683(53.943-398.868)$ \\
Total burn area & 0.077 & 0.005 & 247.429 & $<0.001$ & $1.08(1.07-1.09)$ \\
Full-thickness burn area & 0.080 & 0.004 & 325.271 & $<0.001$ & $1.083(1.074-1.092)$ \\
LOS & -0.008 & 0.005 & 2.183 & 0.140 & $0.992(0.982-1.003)$ \\
Shock & 2.062 & 0.134 & 237.148 & $<0.001$ & $7.865(6.049-10.226)$ \\
\hline
\end{tabular}

Statistical analysis was performed using Multivariate logistic regression. $\mathrm{P}<0.05$ was considered to indicate statistical significance. SE, standard error; LOS, length of hospital stay; OR, odds ratio; CI, confidence interval.

Table VII. Multivariate logistic regression analysis of factors associated with mortality.

\begin{tabular}{|c|c|c|c|c|c|}
\hline Variables & $\begin{array}{l}\text { Regression } \\
\text { coefficient }\end{array}$ & Standard error & Wald & P-value & OR $(95 \% \mathrm{CI})$ \\
\hline Age & 0.530 & 0.181 & 8.530 & 0.003 & $1.699(1.190-2.424)$ \\
\hline Explosion & 2.835 & 0.751 & 14.264 & $<0.001$ & $17.033(3.911-74.182)$ \\
\hline Total burn area & 0.046 & 0.008 & 31.242 & $<0.001$ & $1.047(1.030-1.064)$ \\
\hline Full-thickness burn area & 0.033 & 0.009 & 12.456 & $<0.001$ & $1.034(1.015-1.053)$ \\
\hline LOS & -0.020 & 0.005 & 13.737 & $<0.001$ & $0.980(0.970-0.991)$ \\
\hline Shock & 0.920 & 0.185 & 24.638 & $<0.001$ & $2.509(1.745-3.609)$ \\
\hline
\end{tabular}

Statistical analysis was performed using Multivariate logistic regression. $\mathrm{P} \leq 0.05$ was considered to indicate statistical significance. SE, standard error; LOS, length of hospital stay; OR, odds ratio; CI, confidence interval.

native to this area. Previous epidemiological studies on burn injuries in southwest China, which has unique climatic characteristics, are relatively rare. The Burn Research Institute of Southwest Hospital (Chongqing, China) is the largest burn treatment center in southwest China and has treated a large number of cases that basically reflect the epidemiological characteristics of burn patients in this area $(8,17)$. Therefore, the present study provided an epidemiological analysis of inpatients with burns in southwest China treated from 2009 to 2016 in order to provide suggestions for the further improvement in the treatment as well as the prevention of burns.

With increases in the TBSA, complications were more serious, and the treatment difficulty and the mortality rate gradually increased. Among all of the inpatients treated from 2009 to 2016, the mortality rate was $0.7 \%$, which indicated a significant decline compared with that of mortality rates reported previously (18). With the increase of years, the number of severely burned patients exhibited a downward trend. This result suggests that with recent improvements in burn treatment technology and in the meticulous care of burn patients, the effect of treatment and the overall survival rate have improved. Simultaneously, due to the popularization of knowledge about burns and first-aid techniques, intervention (e.g. cooling) may occur in a more timely manner, leading to a reduction in the severity of burns and the mortality rate.
The mortality of hospitalized burn patients in developing countries, except China, is inconsistent, but overall, it is significantly higher than that in developed countries. Statistics indicate that the fatality rate of hospitalized burn patients ranges from $25.9-43.9 \%$ in Iran to $28.4 \%$ in Kuwait, $33.5 \%$ in Turkey, 27\% in Sri Lanka, 7.4\% in Saudi Arabia, 16\% in Afghanistan, $19.7 \%$ in India and 62\% in Pakistan $(19,20)$. According to recent statistics from a Turkish study, the overall fatality rate of 2,713 burn patients admitted to their unit was only $0.9 \%$ (19). In 2000, the burn-associated mortalities was $\sim 1.36 / 10$ million for males and 1.28/10 million for females (20). Differences in mortality of burn patients based on gender were observed due to males and females having significantly different burn tolerances. More importantly, men are more commonly exposed to heat sources than women, and men engage in more dangerous occupations and tend to be less cautious, suggesting that gender is a factor that accounts for burns (21).

Analysis of the causes of the burn injuries revealed that the majority of injuries were caused by different types of flame burns and hot liquids or vapor $(\sim 40 \%)$, followed by chemical burns (liquefied gas explosion); these results are similar to those of a previous study (22). Patients aged $<15$ years may have experienced burns mostly due to their curious behavior and poor self-control, or due to the negligence of adults. With the increase in age, the number of patients with burn injuries 
decreased, likely due to the growing awareness of the risk of burns. In addition, scalds, which accounted for the largest proportion of burns in this age group, mainly resulted from hot liquids, including hot water, rice porridge and soup (23). Although the incidence rate was high for children, the mortality rate was relatively low. Patients who died of burns were mostly aged 18-59 years, while children and elderly patients less frequently contracted deadly burns. This result may have been due to the fact that individuals aged 18-59 years are more likely to encounter complex environments with an increased risk of being burned. Therefore, the majority of severe burn patients included young adults and middle-aged individuals, and the mortality rate was higher in the young and middle-aged group than that in children and elderly individuals (22).

The present results indicated that children are a major high-risk group in terms of severe burns, which is similar to previous results regarding severe burns in Europe (24). Children with poor self-protection ability and insufficient protection provided by caregivers frequently suffer burns, which should attract widespread attention. Children mainly suffer scalding burns from hot liquids, including hot water, porridge or soup due to curiosity and a poor self-control ability regarding touching objects of interest. Furthermore, the group of 31-50 year-old males with burns comprised a large risk group due to their complex daily living and working environment, which may have increased the possibility of contracting burns. With the increase in age, particularly for middle-aged patients, the function of tissues and organs of the whole body gradually decreased. When the TBSA was $<50 \%$, more burn patients affected and fewer deaths were noted. When the TBSA was $>50 \%$, the risk of poor outcome was higher. Furthermore, when complications were present, the proportion of deaths was significantly increased, indicating that the methods used to treat patients with a large TBSA or large full-thickness burn area require to be improved (22).

According to the cause of injury analysis, the major causes of burns were flames and hot liquids $(\sim 69 \%)$, followed by electricity, chemical burns and explosions; these results were similar to those reported by previous epidemiological studies (25). The incidence of burns was increased in Spring and Summer; one possible reason for this is that thin clothes are worn in the warm weather associated with these seasons, and the cooling time for scalds solutions is prolonged, which may lead to more exposure and a larger burn area after contact with heat and flames. Through further analysis of the causes of burn incidents, we found that more mosquitoes are present in mainland China in the Summer, and mosquito repellent incense is commonly used to repel mosquitoes, which may accidentally ignite clothing, furniture and electrical equipment, and eventually lead to the occurrence of burns.

As an active advocate for the prevention of burns and contributor to the advancement of burn treatments, China has published a similar epidemiological analysis of burn patients to that provided by the present study (26). However, the present study is different from the previous one and has provided novel insight into the epidemiology of burn injury and the efficacy of burn wound management. First of all, the present study contains more data, leading to higher statistical power and allowing for more objective conclusions. Compared with the previous study, further parameters were analyzed; in addition to a summary and analysis of clinicopathological patient characteristics, including patient age, sex, burn area and LOS, the present study also assessed the influence of shock, inhalation injury and complications on the outcome. Furthermore, the present study indicated that there was no statistically significant difference in the causes of burns between males and females in the group aged 0 - 1 years, but in the group aged $\geq 2$ years, there was a statistically significant difference in the causes of burns between males and females. In addition, the proportion of burn patients in the 25-49 year-old group was higher than the other four groups, which may be helpful to formulate prevention and treatment strategies for burns. In addition, significant differences in the TBSA were identified between patients of different ages, which may also provide clues for developing a strategy to prevent burns. At last, in the analysis of risk factors, it was revealed that shock was positively associated with the risk of death of patients with burn injury, while the LOS was a protective factor for the death of burned patients. Furthermore, it is indicated that in 2015/16, the LOS was low and the mortality also, but this was due to different treatment/patient management. It may be reasonable to state that this association cannot be fully proven based on the present data due to inhomogeneous treatment and that this may require elucidation in the future.

In the present study, the clinical data of burn patients treated at Southwest Hospital (Chongqing, China) were retrospectively analyzed. A logistic regression analysis model was used to identify factors associated with death. Explosion, shock, age, TBSA and full-thickness burn area were identified as risk factors for death from a burn. For burn patients after admission, it is therefore important to actively control and deal with the above risk-factors to reduce the incidence of burn-associated mortality. Since the present study is a single burn center study, it has certain shortcomings. Thus, further studies with a larger sample size at multiple centers and levels are required in the future.

According to analyses of the causes of death in recent years, sepsis, single or multiple organ failure and inhalation injury remain the three leading causes of death due to burns. Apart from injuries to the skin or other deeper tissues, burn patients also suffer from inhalation injuries and pathological or physiological disorders that may impair the normal function of organs, which increases the difficulty of clinical treatment (27). Most burn patients suffer from mucosal damage, congestion, edema or lung parenchymal damage due to thermal factors and smoke. In addition, head and neck skin injuries lead to subcutaneous tissue swelling and pressure accompanied by mild inhalation injury or shock, which aggravate the severity of the illness (28). With the increased understanding of inhalation injury and shock, and the improvement of prevention and control measures, great progress has been made in the overall treatment quality, and these injuries are no longer the direct cause of death due to burns (16). However, these complications may cause body tissue ischemia, internal disorders and immune dysfunction resulting in organ failure, which largely hinders the improvement and recovery of burn patients and may even be life-threatening. Under such circumstances, vasoactive substances should be immediately applied to these patients to improve the condition of visceral organs (29). The airways and lungs of burn patients are frequently damaged; failure to clear off exfoliated or necrotic mucosa and secretions may induce severe lung infection due to pathogenic bacteria commonly present in hospitals, including Staphylococcus aureus, 
Pseudomonas aeruginosa and Escherichia coli. The healing times for patients with severe burn wounds are prolonged due to their exposure to the environment, which increases the risk of infection and threatens the lives of patients (30). Therefore, the reasonable use of antibiotics as effective anti-infection treatment methods is important, which is also supported by the results of the present study. In addition to rescue during the shock period, the focus of clinical work should include improvement of the treatment of infection and subsequent complications to reduce the mortality rate of severe burn patients.

\section{Acknowledgements}

Not applicable.

\section{Funding}

No funding was received.

\section{Availability of data and materials}

The datasets used and/or analyzed during the present study are available from the corresponding author on reasonable request.

\section{Authors' contributions}

G-X L and GL conceived the study and provided guidance regarding the analyses; RZ, WQ, TY and LS collected the clinical data; YZ sorted and analyzed the data.

\section{Ethics approval and informed consent}

Not applicable.

\section{Patient consent for publication}

Not applicable.

\section{Competing interests}

The authors have no competing interests to declare.

\section{References}

1. Andrews CJ and Cuttle L: Comparing the reported burn conditions for different severity burns in porcine models: A systematic review. Int Wound J 14: 1199-1212, 2017.

2. http://www.who.int/healthinfo/global_burden_disease/GBD_ report_2004update_full.pdf

3. Page F, Hamnett N, D'Asta F and Jeffery S: Epidemiology of U.K Military Burns 2008-2013. J Burn Care Res 38: e269-e276, 2017.

4. Hashemi SS, Sharhani A,Lotfi B, Ahmadi-Juibari T, Shaahmadi Z and Aghaei A: A systematic review on the epidemiology of pediatric burn in Iran. J Burn Care Res 38: e944-e951, 2017.

5. Emami SA, Motevalian SA, Momeni M and Karimi H: The epidemiology of geriatric burns in Iran: A national burn registry-based study. Burns 42: 1128-1132, 2016.

6. Saaiq M: Epidemiology and outcome of childhood electrical burn injuries at Pakistan Institute of Medical Sciences Islamabad, Pakistan. J Burn Care Res 37: e174-e180, 2016.

7. Akhtar MS, Ahmad I, Khurram MF and Kanungo S: Epidemiology and outcome of chemical burn patients admitted in burn unit of JNMC hospital, Aligarh Muslim University, Aligarh, Uttar Pradesh, India: A 5-year experience. J Family Med Prim Care 142: 106-109, 2015.
8. Wang KA, Sun Y, Wu GS, Wang YR and Xia ZF: Epidemiology and outcome analysis of hand burns: A 5-year retrospective review of 378 cases in a burn center in Eastern China. Burns 41: $1550-1555,2015$

9. Kraenzlin FS, Mushin OP, Ayazi S, Loree J and Bell DE: Epidemiology and outcomes of auricular burn injuries. J Burn Care Res 39: 326-331, 2018.

10. Sheppard NN, Hemington-Gorse S, Shelley OP, Philp B and Dziewulski P: Prognostic scoring systems in burns: A review. Burns 37, 1288-1295, 2011.

11. Kim Y, Kym D, Hur J, Yoon J, Yim H, Cho YS and Chun W: Does inhalation injury predict mortality in burns patients or require redefinition? PLoS One 12: e0185195, 2017.

12. Feng JY, Chien JY, Kao KC, Tsai CL, Hung FM, Lin FM, Hu HC, Huang KL, Yu CJ and Yang KY: Predictors of early onset multiple organ dysfunction in major burn patients with ventilator support: Experience from a mass casualty explosion. Sci Rep 8: 10939, 2018.

13. Wang TH, Jhao WS, Yeh YH and Pu C: Experience of distributing 499 burn casualties of the June 28, 2015 Formosa Color Dust Explosion in Taiwan. Burns 43: 624-631, 2017.

14. Tekin A, Namias N, O'Keeffe T, Pizano L, Lynn M, Prater-Varas R, Quintana OD, Borges L, Ishii M, Lee S, et al: A burn mass casualty event due to boiler room explosion on a cruise ship: Preparedness and outcomes. Am Surg 71: 210-215, 2005.

15. Zhang YH, Guo GH, Shen GL, Han W, Zhao XY, Lin W, Huang $\mathrm{CH}, \mathrm{Xu}$ J, Fan SW and Qian HG: Analysis on treatment of extremely severe burn patients with severe inhalation injury in August 2nd Kunshan factory aluminum dust explosion accident. Zhonghua Shao Shang Za Zhi 34: 455-458, 2018 (In Chinese).

16. Schaefer TJ and Nunez Lopez O: Burns, resuscitation and management, treasure Island (FL): StatPearls Publishing, 2018 01.

17. Ho WS and Ying SY: An epidemiological study of 1063 hospitalized burn patients in a tertiary burns centre in Hong Kong. Burns 27: 119-123, 2001.

18. Huang Y, Zhang L, Lian G, Zhan R, Xu R, Huang Y, Mitra B, Wu J and Luo G: A novel mathematical model to predict prognosis of burnt patients based on logistic regression and support vector machine. Burns 42: 291-299, 2016.

19. Albayrak Y, Temiz A, Albayrak A, Peksöz R, Albayrak F and Tanrikulu Y: A retrospective analysis of 2713 hospitalized burn patients in a burns center in Turkey. Ulus Travma Acil Cerrahi Derg 24: 25-30, 2018.

20. Lionelli GT, Pickus EJ, Beckum OK, Decoursey RL and Korentager RA: A three decade analysis of factors affecting burn mortality in the elderly. Burns 31: 958-963, 2005.

21. Ederer IA, Hacker S, Sternat N, Waldmann A, Salameh O, Radtke $\mathrm{C}$ and Pauzenberger R: Gender has no influence on mortality after burn injuries: A 20 -year single center study with 839 patients. Burns Aug 28, 2018 (Epub ahead of print).

22. Cheng WF, Zhao DX, Shen ZA, Zhang HY, Tu JJ, Yuan ZQ, Duan P and Song GD: An epidemiological investigation of pediatric patients under 14 with large area burns: A multicenter study. Zhonghua Yi Xue Za Zhi 97: 462-467, 2017 (In Chinese).

23. Hussain A and Dunn K: Burn related mortality in greater manchester: 11-year review of regional coronial department data. Burns 41: 225-234, 2015.

24. Dědovic Z, Brychta P, Koupilová I and Suchánek I: Epidemiology of childhood burns at the burn centre in brno, Czech Republic. Burns 22: 125-129, 1996.

25. Liu HF, Zhang F and Lineaweaver WC: History and advancement of burn treatments. Ann Plast Surg 78 (2 Suppl 1): S2-S8, 2017.

26. Li H, Yao Z, Tan J, Zhou J, Li Y, Wu J and Luo G: Epidemiology and outcome analysis of 6325 burn patients: A fve-year retrospective study in a major burn center in Southwest China. Sci Rep 7: 46066, 2017.

27. Hettiaratchy S and Dziewulski P: ABC of burns: Pathophysiology and types of burns. BMJ 328: 1427-1429, 2004.

28. Schaefer $T$ and Burns NLO: Resuscitation and management, 2017.

29. Klein MB, Hayden D, Elson C, Nathens AB, Gamelli RL, Gibran NS, Herndon DN, Arnoldo B, Silver G, Schoenfeld D and Tompkins RG: The association between fluid administration and outcome following major burn: A multicenter study. Ann Surg 245: 622-628, 2007.

30. Toussaint $\mathbf{J}$ and Singer AJ: The evaluation and management of thermal injuries: 2014 update. Clin Exp Emerg Med 1: 8-18, 2014. 